\title{
https://doi.org/10.46813/2020-130-003 \\ TO THE FIFTIETH ANNIVERSARY OF THE KIPT TORSATRON PROGRAM
}

\author{
V.S. Voitsenya, V.E. Bykov, V.A. Rudakov, V.N. Bondarenko, I.E. Garkusha \\ Institute of Plasma Physics NSC “Kharkov Institute of Physics and Technology”, Kharkiv, Ukraine

\section{E-mail: rudakov@kipt.kharkov.ua}

The paper is dedicated to the $50^{\text {th }}$ anniversary of controlled thermonuclear fusion studies performed at the KIPT on the specific stellarator-type experimental installations commonly referred to as "the torsatron". Detailed data are reported on the operating thermonuclear facility "Uragan-2M", the research results obtained with it, and also, the prospects for its use as a reactor. The advantages of the torsatron of this type are described, among them being the wide-range parameter variation capability. This is of importance for finding out the regularities related to plasma stability, heating and confinement.

PACS: $52.55 \mathrm{Hc} ; 52.55 \mathrm{Rk} ; 52.55 \mathrm{Pi}$

\section{INTRODUCTION}

The fusion relevant experimental studies, leaded by K.D. Sinel'nikov, were started in 1956 on the initiative and with support of Academician I.V. Kurchatov [1, 2]. In the course of performing the task set by I.V. Kurchatov, the IPP team has developed and constructed a series of unique stellarator-type setups to study magnetic confinement of high-temperature plasma. Among them, we mention the first KIPT stellarator "Sirius" (E.D. Volkov, R.M. Nikolayev, et al., 1964). It was followed then by the stellarators "Uragan-1" (1967), and its modification "Uragan-2" (1970). The stellarator division was headed by V.A. Suprunenko, the experimental studies were guided by O.S. Pavlichenko.

It stands to mention one of the most important results obtained in the early stages of work. viz., the absence of the Bohm limit of plasma confinement in the stellarator, which was erroneously obtained with the stellarator model-C in the Princeton Plasma Physics Laboratory. The second important result was the development of the way of currentless plasma formation and heating in the toroidal geometry by means of RF methods (O.M. Shvets).

Then followed "Uragan-3", which was the first realization of the "classical" torsatron with the plasmaconfining magnetic field structure having the open divertor configuration. Because of the application of this field structure, the lost from the confinement volume plasma left for the interpolar space without direct contact with the helical conductor surfaces. The plasma flows, going to the space between the helical windings, arrived at the winding casing surfaces beyond the visual line of sight of the plasma confinement volume [3]. Therefore, the erosion products resulting from direct plasma action on the metal surfaces cannot get into the confined plasma.

The creation of the "Uragan-3" has continued the cycle of long-standing studies on the setups of similar configuration constructed at the KIPT. The idea suggested by V.F. Aleksin in 1961 [4] and recognized under the name of "torsatron" in 1968 [5], was tested with plasma experiments in the installations "Saturn" and "Vint-20" (Kharkiv, Ukraine). In Japan, where the magnetic configuration formed by unidirectional helical currents has been named as heliotron, set of facilities of this kind were built in Kyoto (Heliotron-D, HeliotronDM, Heliotron-E, Heliotron-J). The obtained results have confirmed the prospects for developing this line of research for thermonuclear reactor construction. A detailed survey of advances in the torsatron studies as a part of the world stellarator program can be found in ref. [6].

In the eighties, the basic experiments were performed on middle-size installations, e.g., L-2 (Moscow), JIPP T-2 (Nagoya), ATF (Oak Ridge), Heliotron-E (Kyoto), "Uragan-3" (torsatron, Kharkiv), W-7AS (modular stellarator, Garching). Here, noteworthy is the abandonment of the classical stellarator scheme in favor of torsatrons or modular systems.

It has become the grated demand to develop larger installations such as the torsatron Large Helical Device (Japan) with the plasma column of size $\sim 60 \mathrm{~cm}$ (the first plasma in 1988), the modular stellarator Wendelstein 7-X (Garching, FRG) with a mean radius of $53 \mathrm{~cm}$ (the first plasma in December, 2015). At the KIPT plasma division, the development of a relatively large torsatron "Uragan-2M" was also started [7].

The distinguishing feature of the KIPT studies was a close coordination between theoretical investigations, engineering developments, physical experiments and their technological realization. This statement is readily demonstrated by almost simultaneous defense of doctoral theses for the degrees in physics and mathematics (A.A. Shishkin, theory), (E.D. Volkov, experiment), and at some interval, in engineering science (A.V. Georgiyevsky, engineering/technical problems).

\section{THE TORSATRON "URAGAN-2M"}

The idea of constructing a new installation arose already after a short period of "Uragan-3" operation, which, in parallel with the above-mentioned advantages, had an essential fault, namely, a high magnetic field nonuniformity along the length of the installation, and as a consequence, the presence of a large portion of 
locally trapped particles that reduced the plasma confinement efficiency. The fault could be eliminated (to the detriment of the simple design) by using an additional toroidal magnetic field. And this idea, i.e., simultaneous use of a combination of windings that provide independently the helical and toroidal components of the magnetic field, could be realized in the torsatron configuration only through creation of a new installation.

The solution of all complicated problems related to the project development and construction of the new device was entrusted to the "Science and technology division for development of new thermonuclear setups". The Division was organized somewhat earlier at the suggestion of Prof. V.T. Tolok, the head of the Department of Plasma Physics (DPB), and was originally intended for construction and maintenance service of the "Uragan-3" installation (Yu.K. Kuznetsov as a head of the Division).

In the mid 1982, O.S. Pavlichenko held the first meeting devoted to the prospects of creating a new installation. In this and subsequent meetings, Drs. Yu. Kuznetsov, A.V. Georgiyevsky, K.N. Stepanov, E.D. Volkov took part. The discussions have resulted in building up the concept of the installation [8-10]. Much attention was paid to the calculations performed in the A.V. Georgiyevsky's laboratory in close contact with theorists (A.A. Shishkin, V.V. Nemov, D.L. Grekov, V.A. Rudakov). The calculations were aimed at justifying the design of the installation, assigning its modes of operation, and working out the plan of preparing the equipment set for carrying out experimental investigations of the magnetic configuration. The calculations have resulted in the choice of the $l$ value and the helical winding parameters (see below). Special calculations were also required to clarify the role of additional power loads that arise in the magnetic system components in the presence of two magneticconfiguration forming systems. All engineering work at the laboratory was performed owing to the efforts of the groups guided by V.E. Bykov, Yu.F. Sergeyev, Yu.K. Litvinenko in cooperation with the D.V. Efremov Research Institute for Electro-Physical Apparatus (Leningrad), where detailed engineering was also done. Since 1983, the issues of the general implementation and construction of the installation, and also, the increase in the DPB power generating capacity in the power-supply building have become the part of official responsibilities of the Division deputy head V.A. Drunov. The final design of the torsatron U-2M with additional longitudinal magnetic field was adopted in mid 1985.

\section{INSTALLATION PARAMETERS}

$\begin{array}{ll}\text { Major radius of torus, } & R \\ \text { Minor radius of vacuum vessel, } & a_{v} \\ \text { Mean radius of helical winding, } & a_{h} \\ \text { Helical coils number, } & l \\ \text { Magnetic field periods, } & m \\ \text { Calculated (mean) radius of plasma, } a \\ \text { Maximum magnetic field, } \\ \text { Number of compensating field coils, } \\ \text { Number of correcting field coils, }\end{array}$

The special feature of the winding, which provided the helical magnetic field, was the splitting of its helical poles with an angular slot size of $18^{\circ}$. By this means the helical magnetic field nonuniformity was reduced, thereby providing the possibility of introducing additional windows to locate the plasma diagnostic aids.

Figs. 1, 2 show, respectively, the photo of the installation and the layout of its structural elements. The helical winding and the compensating field coils are connected in series. As a result, under all operating conditions the transverse magnetic field produced by the helical winding is compensated automatically. The correcting windings are located in the same stainless steel casings as the compensating windings are: two - in the inner casings with minimum radius of $75.9 \mathrm{~cm}$, and two - in the outer casing with maximum radius of $276.8 \mathrm{~cm}$. The current value was the same for all 4 correcting windings.

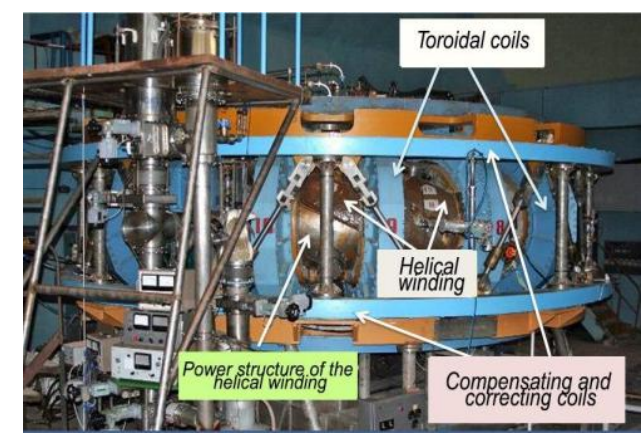

Fig. 1. General view of the "Uragan-2M" installation

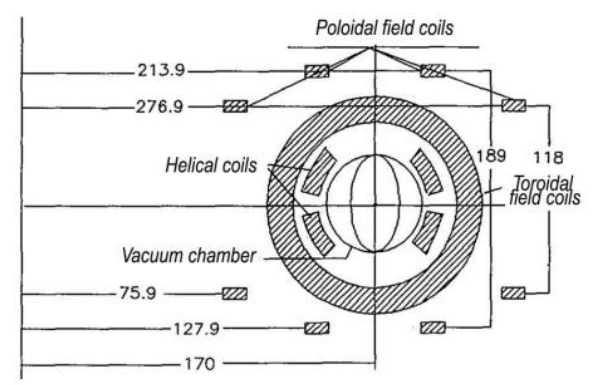

Fig. 2. Cross-section of the installation. The layout of the main structural components is given in centimeters

After deciding on the particular design of the installation, the work started on calculations of the magnetic configuration parameters [11], which were performed in close cooperation with the theorists (A.A. Shishkin, V.V. Nemov, D.L. Grekov). In the process, different calculation methodologies were used: one developed earlier by V.F. Aleksin, V.E. Bykov, and the other developed by N.N. Besedin, G.G. Lesnyakov, and I.M. Pankratov. The comparison between the calculated magnetic-configuration parameters has shown no fundamental differences. However, some differences were observed in the island structure, in particular, in the islands location and size.

The construction of the installation began in 1986 at the "Electric power" plant (Leningrad, Kolpino) with the toroidal magnetic field coil and the load-bearing structure. The vacuum chamber, the transverse 
compensating-field coils with the built-in correcting field windings, the helical winding with its bearing frame were manufactured in Kharkiv (KIPT pilotproduction workshop + KhEhMZ and Ehlektro Tyazh Mash Plants).

The first information about the future installation appeared in 1984 in Leningrad. The international community was first informed about the concept of the installation in 1986 [8] at the Conference in Kyoto (Japan). Publications on the installation design, magnetic configuration structure, and estimates of its effect on plasma confinement appeared well after [912]. The most comprehensive description of the magnetic system of the installation can be found in preprint [11]. Relying on the calculation data, the choice was made on the basic modes of operation, and their characteristics were defined $[12,13]$.

It is known that the parameters of magnetic surfaces (MS) in torsatrons having an additional longitudinal field are determined by two factors : $K_{\varphi}=B_{\varphi} / B_{0}$ and $B_{\perp} B_{0}$. Here $B_{\varphi}$ is the longitudinal magnetic field of the helical winding $(\mathrm{HF}), B_{0}$ is the overall longitudinal field of the helical and toroidal windings (HF), $B_{\varphi}$ and (TF), $B_{\mathrm{t}}$, respectively; $B_{\perp}$ is the total field, perpendicular to the horizontal plane, resulting from the current flows in helical (HF), compensating (VF) and correcting (CF) magnetic field coils..

For numerical studies, two configurations with $K_{\varphi}=0.375$ and $K_{\varphi}=0.295$ were chosen to be basic, thereafter called as "Thin" and "Fat" [9-12] (Table 1).

Table 1

Parameters and physical characteristics of the basic configurations

\begin{tabular}{|c|c|c|}
\hline Parameter & "Thin" & "Fat" \\
\hline$K_{\varphi}=B_{\varphi} / B_{0}$ & 0.375 & 0.295 \\
\hline$B_{\perp} / B_{0}$ & $1.5 \%$ & $2 \%$ \\
\hline$a_{\mathrm{p}}$ & $0.17 \mathrm{~m}$ & $0.25 \ldots 0.27 \mathrm{~m}$ \\
\hline islands & $\mathrm{c}_{\mathrm{s}}=4 / 5$ & $\mathrm{1}_{\mathrm{s}}=1 / 2$ \\
\hline $\mathrm{t}(0) / \mathrm{l}(\mathrm{a})$ & $0.47 / 0.72$ & $0.32 / 0.5$ \\
\hline well & $-2 \%$ & $-3 \ldots 0 \%$ \\
\hline
\end{tabular}

The distinctive property of the "Fat" mode is the decrease in the contribution of helical windings to the longitudinal magnetic field value, and as a result, the increase in the size of the edge unbroken surface (up to 0.25 as compared to $0.17 \mathrm{~m}$ ) at simultaneous decrease in the rotational transform angle on both the axis $1(0)$ and the outer surface $1(a)$. Although the mean plasma radius is in this case substantially smaller than the mean radius of the vacuum chamber $(34 \mathrm{~cm})$, still it must be taken into account that the magnetic surface shape is close to elliptical, so that the outer and the adjacent nearest surfaces extend beyond the volume restricted by the chamber. As a result, the averaged radius of the magnetic surface, being inside the chamber, makes about $0.2 \mathrm{~m}$. The potential full-scale realization of the mode under discussion might be possible only with making a specially shaped chamber (Fig. 3), as suggested in the unrealized "Uragan-4" project [14].

The both modes "Thin" and "Fat" are characterized by the presence of the island structure. For $K_{\varphi}=0.375$ $\mathfrak{l}(0) / \mathrm{l}(\mathrm{a})=0.5 / 0.8$, i.e., conditions are created for the occurrence of sizable islands at $\mathbf{l}=4 / 5,4 / 6,4 / 7$. For $K_{\varphi}=0.295 \mathrm{l}(0) / \mathrm{l}(\mathrm{a})=0.32 / 0.5$, i.e., the islands appear at $\mathbf{l}=2 / 5$ [20]. In both cases, consideration was given to different methods of compensating the island structure. The common feature of the methods considered is the correction of the resulting vertical field.

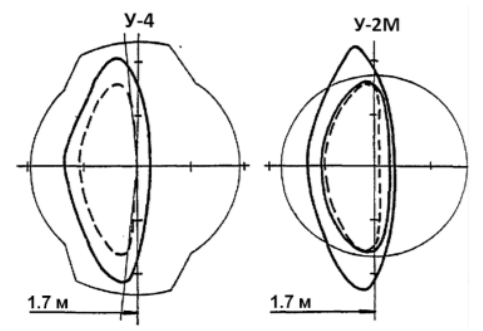

Fig. 3. Vacuum chamber outlines and magnetic surface configurations in $U-4$ and $U-2 M$

On completion of the installation construction in 1991, preparation activities were started for investigating the magnetic configuration parameters of the device [13]. For the two powering modes of magnetic field windings, $K_{\varphi}=0.31$ and $K_{\varphi}=0.375$, data were obtained on the location of the outer magnetic surface in the vertical plane in the cross-section with horizontal position of the major magnetic-configuration axis. The measurements have led to the preliminary conclusion about the absence of any essential errors associated with designing, manufacturing and assembling of the magnetic system for the "Uragan-2m"=M torsatron. The results of more thorough and extensive measurements of the magnetic surfaces structure were reported at the $23^{\text {rd }}$ European Conference on Controlled Fusion and Plasma Physics [15]. For six $K_{\varphi}$ values ranging from 0.275 to 0.375 , the magnetic surface parameters were obtained as functions of the $K_{\varphi}$ value, the mean plasma radius and the magnetic axis position. At $K_{\varphi}=0.295$ and $B \perp / B_{0}=1.85 \%$ the mean radius of the outer unbroken magnetic surface was measured to be 18 to $19 \mathrm{~cm}$, differing but little from the estimated value of $20 \mathrm{~cm}$; and it is significant that the conditions were found, at which there are no magnetic islands: $0.3 \leq K_{\varphi} \leq 0.33$ at $\mathrm{t}(0)<0.5$.

The presence of the additional toroidal field may considerably reduce a strong magnetic field rippling in the near-axis region, which is determined by some special features of the torsatron helical winding. For further reduction of rippling, the "NO MIRROR" mode was proposed in refs. [10, 11, 13]. In this regime the current in the two neighboring toroidal-field coils (located in the region of the maximum helical-winding magnetic field), decreases, while in the two subsequent coils it increases. In particular, for the $K_{\varphi}=0.375$ mode it has been demonstrated that at current ratios of 0.94 and 1.147 to the value of current at consecutive commutation of all the coils (1.00), the ripples in the vicinity of the magnetic axis get considerably reduced (about six times less) as compared with a standard configuration. Accordingly, neoclassical plasma losses should be also considerably reduced. The relationship of the mentioned coil current values $\left(1.22\right.$ for $\left.K_{\varphi}=0.375\right)$ decreases with decreasing $K_{\varphi}$. 
It should be noted that performing all the calculations became possible owing to a fruitful cooperation of the PPB KIPT staff with the theorist groups of the Stellarator Department of the M. Planck Institut für Plasmaphysic (Garching, Germany), Oak Ridge National Laboratory (USA), Keldysh Institute of Applied Mathematics, Institute of General Physics RAS (Moscow, RF), I.V. Kurchatov Institute of Atomic Energy (since 1991 called as Russian Science Center "Kurchatov Institute").

As early as at the stage of initial magnetic configuration experiments it has been found that the holder, support of the helical winding fails to provide the operation of the facility at full power conditions (peak modes). Therefore, the decision on modernization of the installation was taken. The upgrading work was completed at the end of 2006.

In spite of the engineering measures taken to ensure the accuracy of manufacturing the magnetic system, the uncontrollable deviations from the design data are unavoidable when assembling such a complex setup. Therefore, the magnetic field structure was re-examined under different modes with the same method as that in experiments of ref. [16]. Measurements of the mean radius of the outer magnetic surface (a) and the magnetic axis displacement $(\Delta)$ were performed as functions of the transverse magnetic field. The measurement data have demonstrated that after the installation reassembling, the magnetic configuration and its parameters remained practically unchanged. The analysis of the obtained data has led to the following basic mode of operation for the U-2M: $K_{\varphi}=0.31$, $<B_{\perp}>/ \mathrm{B}_{0} \approx 2.55 \%$, Fig. 4,a [16].
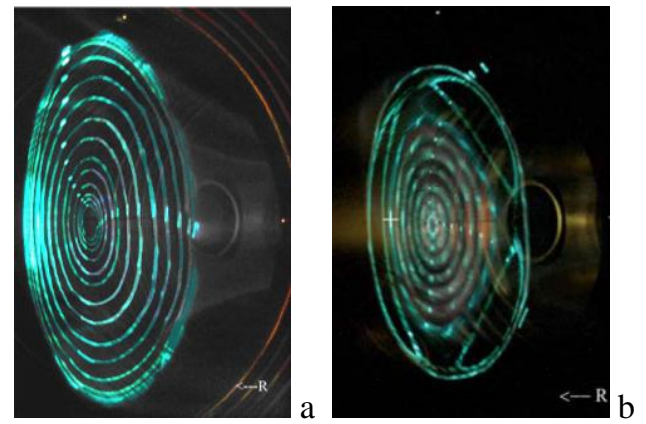

Fig. 4. Magnetic surafces for different modes. $a: K_{\varphi}=0.31,\left\langle B_{\perp}>/ B_{0} \approx 2.55 \%\right.$. The mean radius of the outer magnetic surface is $\approx 20.5 \mathrm{~cm}$;

$$
b: K_{\varphi}=0.32,<B_{\perp}>/ B_{0} \approx 1.58 \%
$$

Immediately on completion of magnetic measurements, the investigations on plasma creation by RF methods were started. Simultaneously, calculations were continued as to the capabilities of the installation to perform experiments at other modes, too. From the calculations it follows that the "Uragan-2M" makes it possible, at the cost of its minor reconstruction, to carry out plasma experiments for different configurations.

\section{CHANGE IN THE ISLAND STRUCTURE}

$$
[9-12,17]
$$

The mode, under which the island structure is substantially suppressed, can be attained through adjusments the currents in the correcting windings. The intensification of the island structure (see Fig. 4,b) provides the conditions for realization of the island divertor [17]. This makes it possible to investigate the influence of the island structure on the "global" plasma behavior in the installation.

\section{CURRENT DISBALANCE IN HELICAL WINDING POLES}

1. The change in the magnetic configuration characteristics as a result of current matching in one of the helical winding poles. The magnetic configuration under this mode is similar to the "hybrid torsatron" configuration, i.e., the torsatron with two helical windings, one of which is with $l=2$ (usual as in $\mathrm{U}-2 \mathrm{M}$ ), and the other is $l=1$ (having similar parameters, and combined with one of the poles of the $1=2$ winding with the reverse current flow in it). The realization of this scenario is possible due to power supply of the poles from different sources. In this case, a part of the compensation winding is in series connected with one of the poles, whereas the remaining part of the winding, e.g., VF1, VF4, VF5, VF8, and VF2, VF3, VF6, VF4, is connected consecutively with the second pole.

2 . The limiting case of disbalance is the reduction of current to zero in one of the poles, this being equivalent to the $l=1$ torsatron. In this case, the current in the compensating windings must be reduced by a factor of 2 , and that can be readily attained through parallel connection of the identical coils.

\section{U-2M OPERATION UNDER A PURELY STELLARATOR MODE}

1. The powering of each of the helical winding halves with currents of opposite directions allows one to convert the $\mathrm{U}-2 \mathrm{M}$ into an $l=2$ stellarator [17].

2. With energization of helical winding poles by oppositely directed currents, the configuration of the $l=1$ stellarator can be realized. This eliminates the necessity of the compensating winding for the both stellarator regimes.

\section{MAGNETIC CONFIGURATION FOR THE MODE OF PLASMA CONFINEMENT IN THE VOLUME REMOTE FROM THE CHAMBER WALLS}

At opposite direction of the helical-winding longitudinal field and the additional toroidal field $K_{\varphi}<0$, the mode of plasma confinement can be realized in the volume remote from the chamber walls [19]. A similar result is achieved at aiding connection of helical and toroidal fields for $K_{\varphi}$ above the mode of operation. The calculations for $K_{\varphi}=0.43$ [20] have shown the approximate equality of surface dimensions as compared to the $K_{\varphi}=-014$ mode.

\section{DIFFERENT MODIFICATIONS OF THE ADDITIONAL TOROIDAL FIELD}

1. The modes "NO mirror" and "HIGH mirror" considered in refs. $[9,11,12]$ can be realized with relative ease.

2. The properties of the "Uragan-2M" magnetic system allow one to suggest it as a constituent part of the stellarator - mirror thermonuclear hybrid (SPTH) with the special features described below. To locate the 
open trap, where the neutron production takes place, it is necessary to provide nearly a two-fold "dip" of the confining magnetic field. This effect can be attained either by disconnecting one coil or by parallel connection of two neighboring coils (Fig. 5). The both variants provide the necessary field reduction. Note that at parallel connection the reduction is somewhat lower (see Figs. 5-1), and there are the closed magnetic surfaces, the size of which is somewhat smaller than under the standard mode. The measured surfaces are in agreement with the calculated data (see Figs. 5-2).

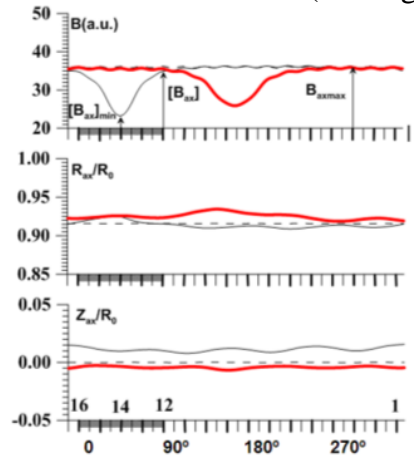

Fig. 5-1. Longitudinal field distribution. Black curves correspond to disconnection of one coil, red curves - to parallel connection of two coils
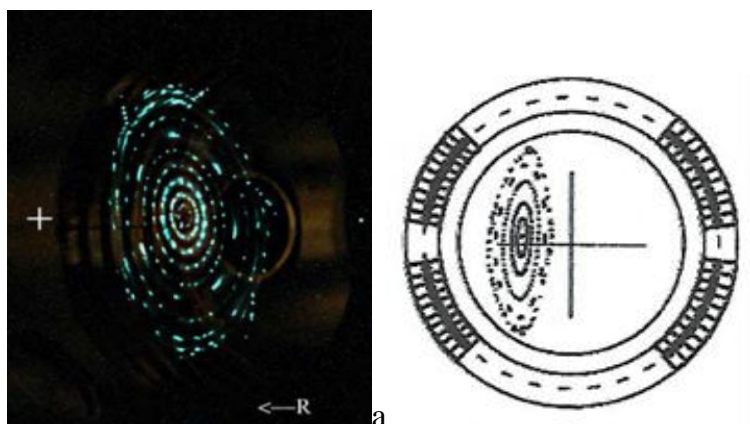

Fig. 5-2. Measured (a) and Calculated (b) magnetic surfaces $\varphi=\pi$, with one coil switched off

At present, "Uragan-2M" is the operating thermonuclear installation of the IPP NSC KIPT, where plasma confinement studies are successfully carried out. From the date of physical start-up numerous experiments were made, with the findings represented in multiple publications in scientific journals, and in the reports contributed to international conferences.

The installation now operates at a reduced magnetic field $(\mathrm{B}<1 \mathrm{~T})$. Unfortunately, the technical capabilities of power sources restrict the facility operation at full power. Nevertheless, in its parameters and experimental functionality, the "Uragan-2M" comes under the notion of advanced thermonuclear installations [25-32].

\section{REACTOR PROSPECTS OF THE INSTALLATION}

Virtually in each of the countries concerned with plasma studies in stellarators, simultaneous activities are under way to develop the projects of nuclear-fusion reactors. As a general rule, the experimental investigations of plasma are carried out at the installations, the structure of which shows the reactor prospects. The two largest, now-in-operation installations (LHD, Japan and Wandelstein VIIX, FRG) have become the prototypes in the development of the LHR-S and Helias (HRS) fusion reactor projects.

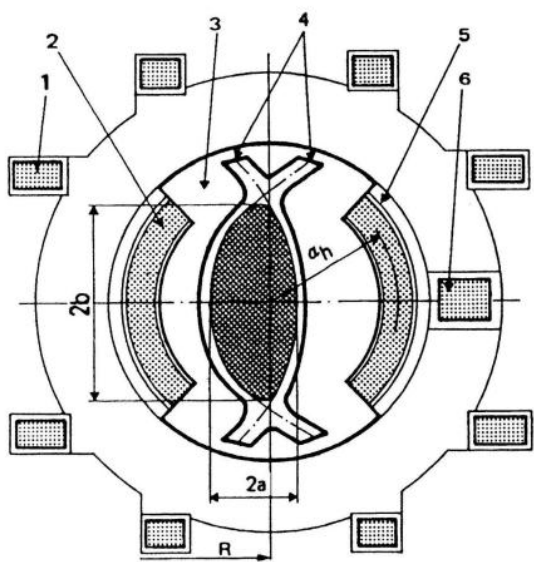

Fig. 6. $U-2 M R$ reactor configuration:

1 - compensating conductor; 2 - helical winding,

3 -blanket; 4 -divertor; 5 -load-carrying structure;

$$
6 \text { - toroidal coil cross-section }
$$

Concurrent with the foreign projects, the work on the development of the reactor-stellarator was being performed at the Plasma Physics Branch of the KIPT AS UkSSR in cooperation with the D.V. Yefremov Research Institute of Electrophysical Apparatus (St. Petersburg). As a result, the structure of the modular reactor-torsatron magnetic system has been developed. In the properties of its magnetic configuration it approaches the properties of the magnetic system of the $l=3$ torsatron with continuous helical conductors, the operating torsatron "Uragan-3M" serving as a prototype $[23,29]$.

Simultaneously with implementing the idea of the torsatron with an additional longitudinal field, consideration was given to the feasibility of building the fusion reactor with similar installations as the base. The results of the first works were reported at the international conference in Yalta (1986) [24] and were published in Phys. Technology [9]. The cross-section of the proposed reactor is shown in Fig. 6, and its parameters are given in Table 2.

Table 2

Parameters of the reactor $U-2 M R$ with an additional longitudinal field

\begin{tabular}{|l|c|c|}
\hline Parameters & Dim & Value \\
\hline Major radius of the torus & $\mathrm{m}$ & 15 \\
\hline Radius of helical winding & $\mathrm{m}$ & 3,8 \\
\hline Mean radius of plasma & $\mathrm{m}$ & 1.6 \\
\hline Magnetic field on the pole axis & $\mathrm{T}$ & 5 \\
\hline Rotational transformation: & - & \\
- at plasma boundary & - & 0.73 \\
- on the magnetic axis & & 0.57 \\
\hline$\beta$ & & 8 \\
\hline Helical ripple amplitude, $\varepsilon_{\mathrm{h}}$ & $10^{20} \mathrm{~m}^{-3}$ & 0.05 \\
\hline Plasma density & $\mathrm{keV}$ & 2.5 \\
\hline Plasma temperature & $\mathrm{s}$ & 10 \\
\hline Energy confinement time & $\mathrm{GW}$ & 3.8 \\
\hline Reactor thermal output & &
\end{tabular}


The reactor parameters were calculated on the assumption of realization of neoclassical transport processes. Besides, the possibility was demonstrated for implementing the hybrid fusion reactor (Fig. 7) on the basis of the torsatron having an additional longitudinal field, the detailed description of which can be found in ref. [25, 33, 34].

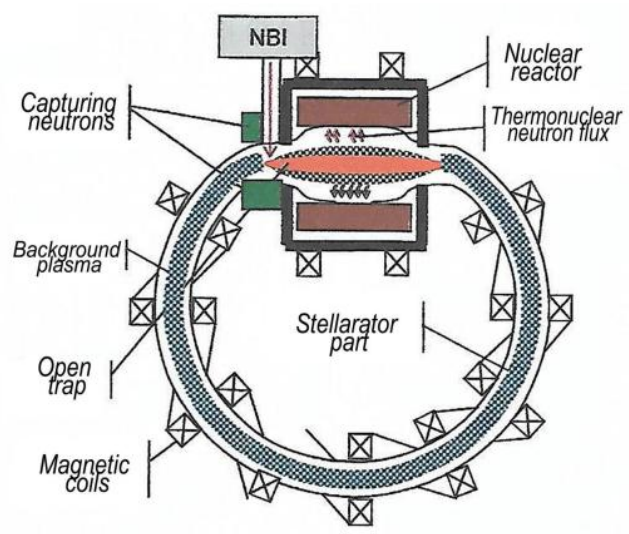

Fig. 7. Schematic arrangement of the stellarator-mirror hybrid fusion reactor

\section{CONCLUSIONS}

The stellarator-type magnetic traps and their varieties, known as torsatrons, remain among the most promising systems, around which the solution of the problem of controlled thermonuclear fusion (CTF) can be worked out. The "Uragan-2M" investigations have given a great number of results being directly relevant to the solution of the CTF problem. The U-2M facility remains one of a few stellarator-type installations, which still continue to be involved in intensive plasma physics studies, aimed at solving the controlled fusion problems.

The authors find it necessary to note that the present paper was the finishing touch of the multi-year scientific work of Dr. V.S. Voitsenya, who passed away in the $86^{\text {th }}$ year of life after a siege of illness and missed the chance to see this publication in the finished appearance.

\section{REFERENCES}

1. V.T. Tolok, V.S. Kogan, V.V. Vlasov. Physics and Kharkov. Ed. A.N. Timchenko, Kharkov, 2009, 409 p.

2. I.E Garkusha. To the 25-th anniversary of the Institute of Plasma Physics of the National Science Center "Kharkov Institute of Physics and Technology // Problems of Atomic Science and Technology. Series «Plasma Physics». 2019, № 1, p. 267-271.

3. V.S. Voitsenya, V.E. Bykov, V.V. Chechkin, L.I. Grigor'eva, O.S. Pavlichenko, A.F. Shtan', A.I. Skibenko, S.I. Solodovchenko, E.V. Trofimenko, E.D. Volkov. The review on experimental studies of divertor flows in Kharkov stellarator-type devices. Preprint KFTI 94-18, Kharkov, 1994, 27 p.

4. V.F. Aleksin. Calculation of the stellarator magnetic field // ZhTF. 1961, v. 31, № 11, p. 1284-1288.

5. C. Gourdon, D. Marty, E.K. Maschke, J. Touch. The torsatron without toroidal field coils as a possible solution to the divertor problem // Nucl. Fusion. 1971, v. 11, № 2, p. 161-166.

6. A.V. Georgiyevskiy, V.A. Rudakov, V.T. Tolok. Development of a conception of the stellarator based on torsatron and modular systems // Problems of Atomic Science and Technology. Series «Plasma Physics». 2003, № 1, p. 7-12.

7. V.E. Bykov et al. The torsatron project with an additional longitudinal field the "Uragan-2M" installation // Report at the III All-Union Conference on engineering problems of thermonuclear reactor, Leningrad, 1984, v. 1, p. 61.

8. V.E. Bykov, A.V. Georgievskij, V.V. Demchenko, Yu.K. Kuznetsov, Yu.A. Litvinenko, A.V. Longinov, et al. URAGAN-2M, $l=2$ Torsatron with an Additional Toroidal Field // Proceedings of International Stellarator / Heliotron Workshop, Kyoto, Japan, November 25-28, 1986, PPLK-5, v. I, p. 300, Kyoto University.

9. V.E. Bykov, A.V. Georgievskij, V.V. Demchenko, Yu.K. Kuznetsov, Yu.A. Litvinenko, A.V. Longinov, et al. URAGAN-2M: A Torsatron with an Additional Toroidal Field // Fusion Technology. 1990, v. 17, p. 140-147.

10. C.D. Beidler, N.T. Besedin, V.E. Bykov, D.A. Carreras, N. Dominguez, et al. Physics studies for the "Uragan-2M" torsatron // Paper IAEA-CN-53/C-IV6 in Proceedings of $13^{\text {th }}$ International Conference on Plasma physics Controlled and Nuclear Fusion Research, Washington 1-6 Oct. 1990. Nuclear Fusion Supplement 1991, p. 663-675.

11. A.A. Shishkin. Torsatron-type system with the small pitch angle of helical windings and additional toroidal field coils: Preprint KhIPT 2005-2, Kharkov, 2005, p. 34 .

12.V.E. Bykov, A.V. Georgievskij, Yu.K. Kuznetsov, et al. Analysis of the "Uragan-2M" torsatron magnetic configuration // Problems of Atomic Science and Technology. Series «Thermonuclear fusion». 1988, v. 2, p. 17-21.

13. O.S. Pavlichenko for the U-2M group. First results from the URAGAN-2M torsatron // Plasma Phys. Control. Fusion. 1993, v. 35, p. B223-B230.

14. V.E. Bykov, A.V. Georgievsky, A.V. Khodyachikh, Yu.K .Kuznetsov, Yu.A. Litvinenko, O.S. Pavlichenko, V.G. Peletminskaya, Yu.F. Sergeev, A.A. Shishkin, V.G.Smirnov, F.A. Tkhoryak. Uragan-4 project. Kharkov 27-31 May 1991. Published in Vienna, July 1991, p. 447-450.

15. G.G. Lesnyakov, N.T. Besedin, Yu.K. Kuznetsov, E.D. Volkov, O.S. Pavlichenko. Studies of magnetic surfaces in the Uragan-2M torsatron // Contributed Papers of $23^{\text {rd }}$ EPS Conf. on Contr. Fusion and Plasma Phys. Kiev, 1996, V. 20 C, Part. II (b025), p. 547-550.

16. A.A. Beletskii, V.L. Berezhnyj, P.Ya. Burchenko, V.V. Chechkin, V.Ya. Chernyshenko, L.I. Grigor'eva, et al. First results of the renewed Uragan-2M torsatron // Problems of Atomic Science and Technology. Series «Plasma Physics». 2008, № 6, p. 13-15.

17. G.G. Lesnyakov, A.N. Shapoval, O.S. Pavlichenko. Feasibility of creating an island divertor in the URAGAN-2M torsatron // Problems of Atomic Science 
and Technology. Series «Plasma Physics». 2012, № 6, p. 34-37.

18. V.M. Zalkind, V.G. Kotenko, S.S. Romanov. Magnetic surfaces of the $l=2$ stellarator with shifted helical windings // Problems of Atomic Science and Technology. Series «Thermonuclear fusion». 2008, № 4, p. 67-75.

19. V.G. Kotenko, E.D. Volkov, K. Yamatsaki. Eventual approach to the problem of commercial nuclear fusion based on closed magnetic systems // Problems of Atomic Science and Technology. Series «Thermonuclear fusion». 2004, № 3, p. 29-37.

20. V.G. Kotenko, V.E. Moiseenko. Edge magnetic island excitation in the U-2M torsatron // Problems of Atomic Science and Technology. Series «Plasma Physics». 2016, № 6, p. 25-28.

21. G.G. Lesnyakov, A.N. Shapoval, S.P. Gubarev, M.S. Zolototrubova, G.P. Opaleva, M.N. Makhov, V.G. Kotenko, V.E. Moiseenko, V.S. Voitsenya. Magnetic surfaces of stellarator-mirror hybrid in the Uragan-2M torsatron // Problems of Atomic Science and Technology. Series «Plasma Physics». 2013, № 1(83), p. 57-60.

22. V.G. Kotenko, V.E. Moiseenko, E.L. Sorokovoy. Torsatron U-2M magnetic surfaces with enhanced mirror ratio // Problems of Atomic Science and Technology. Series «Plasma Physics». 2018, № 6, p. 21-23.

23. V.E. Bykov, E.D. Volkov, A.V. Georgievskij, G.S. Yemel'yanov, V.V. Kantan, A.V. Komin, M.V. Krivosheyev, A.B. Mineyev, V.A. Rudakov, et al. The thermonuclear reactor-torsatron: Invention Certificate № 1050419. Priority date: 15 March, 1982.

24. E.D. Volkov, A.V. Georgievskij, Yu.K. Kuznetsov, Yu.A. Litvinenko, O.S. Pavlichenko, V.A. Rudakov, Yu.F. Sergeev. Fundamental conceptions of a reactortorsatron with an additional longitudinal field // Proc. 4-th technical committee meeting and workshop on fusion reactor design and technology, Yalta, 26 May-6 June 1986, IAEA, Vienna, v. 1, p. 393-402.

25. V.E. Moiseenko, K. Noack, O. Ågren. StellaratorMirror-Based Fusion-Driven Fission Reactor // Journal of Fusion Energy. 2010, v. 29, p. 65-69.

26. V.E. Moiseenko et al. RF plasma production and heating below ion-cyclotron frequencies in Uragan torsatrons // Nuclear Fusion. 2011, v. 51, p. 083036.

27. V.E. Moiseenko et al. Progress in stellarator research at IPP-Kharkov // Nukleonika. 2016, v. 61(2) p. 91-97.

28. G.P. Glazunov et al. Characterization of wall conditions in Uragan-2M stellarator using stainless steel thermal desorption probe // Fusion Engineering and Design. 2018, v. 137, p. 196-201.

29. V.E. Moiseenko et al. Characteristics of regular discharges in "Uragan-3M" torsatron // Plasma Physics and Controlled Fusion. 2019, v. 61(6), p. 065006.

30. V.E. Moiseenko et al. Stellarator research at IPP KIPT: Status and prospects // Problems of Atomic Science and Technology. Series «Plasma Physics». 2019, v. 119(1), p. 3-8.

31. V.E. Moiseenko et al. VHF discharges for wall conditioning at the Uragan-2M torsatron // Nuclear Fusion. 2014, v. 54(3), p. 033009.

32. V.S. Voitsenya et al. Progress in stellarator research in Kharkov IPP // Physica Scripta. 2014, v. T161, p. 014009.

33. V.E. Moiseenko et al. Fast ion motion in the plasma part of a stellarator-mirror fission-fusion hybrid // Plasma Physics and Controlled Fusion. 2014, v. 58(6), p. 064005.

34. V.E. Moiseenko et al. Research on stellaratormirror fission-fusion hybrid // Plasma Physics and Controlled Fusion. 2014, v. 56(9), p. 094008.

Article received 25.10 .2020

\section{К 50-ЛЕТИЮ ТОРСАТРОННОЙ ПРОГРАММЫ ХФТИ}

\section{В.С. Войценя, В.Е. Быков, В.А. Рудаков, В.Н. Бондаренко, И.Е. Гаркуиа}

Работа посвящена 50-летию исследований в ХФТИ по проблеме управляемого термоядерного синтеза на экспериментальных установках специальной конструкции, которую принято называть торсатроном. Подробно освещены особенности конструкции действующей термоядерной установки торсатрона "Ураган2M”, результаты исследований на ней и ее реакторные перспективы. Отмечены достоинства такого типа устройства, выражающиеся в возможностях широкого изменения параметров, что важно для установления закономерностей, связанных с устойчивостью, нагревом и удержанием плазмы.

\section{ДО 50-РІЧЧЯ ТОРСАТРОННОЇ ПРОГРАМИ ХФТІ}

\section{В.С. Войценя, В.С. Биков, В.А. Рудаков, В.Н. Бондаренко, І.С. Гаркуиа}

Робота присвячена 50-річчю досліджень у ХФТІ з проблеми керованого термоядерного синтезу на експериментальних установах спеціальної конструкції, яку прийнято називати торсатроном. Детально освітлені особливості конструкції діючої термоядерної установки торсатрона “Ураган-2М”, результати досліджень на ній та їі реакторні перспективи. Відзначені достоїнства такого типу пристрою, що виражаються в можливостях широкої зміни параметрів, що важливо для встановлення закономірностей, пов'язаних із стійкістю, нагрівом і утриманням плазми. 